\title{
Similar serological response to conventional therapy for syphilis among HIV-positive and HIV-negative women
}

Johan Goeman, Mayimona Kivuvu, Nzilambi Nzila, Frieda Behets, Bazepeyo Edidi, Emannuel Gnaore, Eddy Van Dyck, Michael St. Louis, Peter Piot, Marie Laga
Projet SIDA, Ministry of Health, Kinshasa, Zaire

J Goeman

M Kivuvu

N Nzila

F Behets

B Edidi

M St. Louis

Department of

Infection and

Immunity, WHO

Collaborating Centre

on AIDS, Institute of

Tropical Medicine,

Antwerpen, Belgium

J Goeman

F Behets

E Gnaore

E Van Dyck

P Piot

M Laga

Division of HIVIAIDS, International Activity, Centers for Disease

Control, Atlanta,

Georgia, USA

M St. Louis

Present affiliation :

Frieda Behets is now with the University of North

Carolina, Chapel Hill, USA.

Emmanuel Gnaore is now director of the Programme National de Lutte contre le SIDA, Ministry of Health, Ivory Coast.

Michael St. Louis is now

with the Division of
STD/HIV Prevention at the

Centers for Disease Control, Centers for Diseas
Atlanta, USA

Peter Piot is now Director, Joint and Cosponsored UN

Program on HIV/AIIS,

Program on HIV/AIDS,

Address for correspondence: Dr Marie Laga,

Department of Infection

and Immunity, WHO

Collaborating Centre on

AIDS, Institute of Tropical

Medicine

155 B-2000 Antwerpen,

Belgium.

\begin{abstract}
Objectives-To compare characteristics of syphilis serological reactivity in HIV positive (+) and HIV negative $(-)$ female sex workers, as well as the serological response to therapy after treatment with intramuscular benzathine penicillin, 2.4 million $U$ weekly, for three consecutive weeks.

Methods-Rapid plasma reagin (RPR) and Treponema pallidum haemagglutination assay (TPHA) results of 72 HIVpositive and 121 HIV-negative women reactive in both tests were assessed. The response to therapy was prospectively monitored with quantitative RPR serology in 47 HIV-positive and 73 HIV-negative patients. Cumulative probabilities of becoming nonreactive by RPR were compared at six months, one and two years after therapy.

Results-At enrolment, the geometric mean titres of RPR and TPHA were lower in HIV-positive patients (RPR, 1:2.6) than in HIV-negative patients (RPR, 1:3.8; $p<0.01$ ). The evolution over time of RPR titres was similar among HIV-positive patients as compared to HIV-negative patients. Among patients with an initial RPR titre of $<1: 8,53 \%$ of HIV-positive and $44 \%$ of HIV-negative patients became RPR negative two years after therapy. Among patients with an RPR titre of 1:8 or greater at enrolment, $83 \%$ of HIV-positive and $90 \%$ of HIVnegative patients had reached at least a fourfold decline of RPR titres two years after therapy.

Conclusions-Syphilis serology findings (both RPR and TPHA) may be altered in the presence of HIV infection, but the serological response to therapy was similar in HIV-positive and HIV-negative patients.
\end{abstract}

(Genitourin Med 1995;71:275-279)

Keywords: Syphilis, HIV, Serology, Zaire

\section{Introduction}

Since the emergence of the AIDS epidemic, syphilis has attracted renewed attention. Not only has it been shown that genital ulcers facilitate the transmission of human immunodeficiency virus (HIV), ${ }^{1-4}$ but there is also considerable concern about the impact of
HIV infection and related immune deficiency on the natural history of syphilis. ${ }^{45} \mathrm{~A}$ more aggressive course and unusual clinical presentations have been suspected in HIVseropositive individuals, and neurological complications have been reported to be more frequent and to occur at an earlier stage in HIV-positive subjects than in HIV-seronegative patients. ${ }^{6-8}$ The decreased immune functions of HIV-positive patients may alter the response to treatment, especially to the single dose therapy recommended for primary and secondary syphilis. ${ }^{10}$ Serological tests for the diagnosis of syphilis and for monitoring of antimicrobial therapy may also be impaired, although this again remains controversial. ${ }^{11-13}$ Finally, although serological monitoring of syphilis therapy is recommended, the evolution of serological responses is not well documented, even in patients without HIV infection.

In order to assess whether the serological response to treatment of syphilis in HIV-positive subjects is impaired, we compared the evolution of RPR titres after treatment in HIV-positive and HIV-negative women with reactive syphilis serology in Kinshasa, Zaire.

\section{Methods}

Study population

Study participants were female sex workers who attended the Women's Health Centre of Matonge in Kinshasa, Zaire, and gave informed consent. Initially, a cross sectional survey was performed among 1233 women, to document prevalence rates of various sexually transmitted diseases (STDs). ${ }^{14}$ Subsequently a cohort study was established to study the impact of STD control and condom promotion on the sexual transmission of HIV. ${ }^{15}$ Women with both positive rapid plasma reagin (RPR) and Treponema pallidum haemagglutination (TPHA) serology at enrolment were considered to have active syphilis. The history of earlier syphilis treatment was unknown.

\section{Study design}

All women with a reactive syphilis serology, enrolled in the larger cohort study, were treated with intramuscular injections of benzathine penicillin G, 2.4 million units weekly for three consecutive weeks according to the guidelines of the Centers for Disease Control and the World Health Organization..$^{9}{ }^{10}$ The evolution of RPR titres in HIV-positive patients was compared with those among 
HIV-negative patients after six, 12 and 24 months.

At the enrolment visit consenting women answered a questionnaire regarding demographic characteristics, gynaecological history, prostitution, sexual practices and medical history. A gynaecological examination was performed and samples were taken for detection of STD. Blood was drawn for serology of HIV, syphilis and Haemophilus ducreyi infection. Women in whom both RPR and TPHA were positive were considered to have active syphilis, and were asked to participate in a prospective study to monitor the response to treatment. Patients were asked to return for monthly follow-up visits for health education, condom distribution and management of STD, and each third month blood was drawn for HIV and syphilis serology. Only patients who were followed up for at least six months were included in the analysis of therapy outcome. For this analysis, patients were divided into two groups by RPR titre at enrolment, including women with an RPR titre of less than $1: 8$, and women with an RPR titre of $1: 8$ or more. Adequate serological response to therapy was defined as an RPR result becoming negative in the first group, or the RPR titre showing a fourfold decline in the second group. The study was approved by the national ethics committee of the Ministry of Health of Zaire.

\section{Laboratory procedures}

Serology was performed at the laboratory of Projet SIDA in Kinshasa. The study tests were commercially available kits. The rapid plasma reagin (RPR) test from Becton-Dickinson, Baltimore, Maryland and

Table 1 Comparison of women with reactive [RPR and TPHA] to women with negative $R P R$ at enrolment

\begin{tabular}{|c|c|c|c|}
\hline & $\begin{array}{l}\text { RPR and TPHA } \\
\text { positive } \\
(n=193)\end{array}$ & $\begin{array}{l}R P R \text { test } \\
\text { negative } \\
(n=1040)\end{array}$ & p-value \\
\hline \multicolumn{4}{|l|}{ Demographic characteristics } \\
\hline Zairian nationality & $96 \%$ & $95 \%$ & NS \\
\hline Age (years, SD) & $28(7)$ & $25(7)$ & $<0.001$ \\
\hline Never been to school & $49 \%$ & $33 \%$ & $<0.001$ \\
\hline $\begin{array}{l}\text { Age at first sexual intercourse } \\
\text { (years, }(\mathrm{SD}))\end{array}$ & $14(2)$ & $15(2)$ & NS \\
\hline Mean number of pregnancies (SD) & $3(2)$ & $3(2)$ & NS \\
\hline One or more children died & $45 \%$ & $35 \%$ & 0.01 \\
\hline $\begin{array}{l}\text { One or more spontaneous abortions } \\
\text { Characteristics related to prostitution }\end{array}$ & $17 \%$ & $14 \%$ & NS \\
\hline \multicolumn{3}{|l|}{ Type of prostitution } & 0.02 \\
\hline Hotel & $50 \%$ & $58 \%$ & \\
\hline Home & $45 \%$ & $35 \%$ & \\
\hline Street & $5 \%$ & $7 \%$ & \\
\hline Months in prostitution (median) & 48 & 36 & $<0.001$ \\
\hline Number of clients per week (mean, SD) & $8(8)$ & $8(8)$ & NS \\
\hline \multicolumn{4}{|l|}{$\begin{array}{l}\text { Sexual practices: } \\
\text { Sel week (IIICan, OD) }\end{array}$} \\
\hline Vaginal sex (ever) & $100 \%$ & $100 \%$ & NS \\
\hline Oral sex (ever) & $20 \%$ & $26 \%$ & NS \\
\hline Anal sex (ever) & $7 \%$ & $16 \%$ & 0.003 \\
\hline Sex during menses (ever) & $62 \%$ & $56 \%$ & NS \\
\hline Regular condom use & $8 \%$ & $13 \%$ & NS \\
\hline \multicolumn{4}{|l|}{ Sexually transmitted diseases } \\
\hline Neisseria gonorrhoeae & $19 \%$ & $24 \%$ & NS \\
\hline Chlamydia trachomatis & $10 \%$ & $14 \%$ & NS \\
\hline Trichomonas vaginalis & $22 \%$ & $22 \%$ & NS \\
\hline Candida albicans & $8 \%$ & $10 \%$ & NS \\
\hline Presence of genital ulcer & $7 \%$ & $4 \%$ & NS \\
\hline History of genital ulcer (last 5 yrs) & $43 \%$ & $39 \%$ & NS \\
\hline Positive $H$ ducreyi serology & $87 \%$ & $62 \%$ & $<0.001$ \\
\hline Pubic lice (last 5 yrs) & $62 \%$ & $48 \%$ & $<0.001$ \\
\hline HIV infection & $37 \%$ & $35 \%$ & NS \\
\hline
\end{tabular}

the Treponema pallidum haemagglutination (TPHA) test from Fuji-Rebio, Japan were used for syphilis serology. Sera were tested for HIV antibody by EIA (Vironostika Organon Tecknika, the Netherlands) and positive EIA results were confirmed by Western blot analysis (Du Pont de Nemours, Wilmington, Delaware). Diagnosis of other sexually transmitted diseases was performed at the same laboratory, as described elsewhere. ${ }^{14}$

\section{Statistical analysis}

The Chi square, Fisher exact test, the $t$ test and the Wilcoxon 2-sample test were used as appropriate. The evolution of the RPR titres in the different groups was compared using the actuarial life table method. ${ }^{16}$ If a patient did not present at one or more of the intermediate visits (that is, month 6 and/or month $12)$, then the latest known RPR titres were considered for evaluation. Once a patient met the serological criteria for "adequate response", she was considered to be reacting successfully to treatment.

\section{Results}

Characteristics of syphilis patients at enrolment Out of 1233 women enrolled in the cross sectional study, 193 (16\%) had both positive RPR and positive TPHA results and another $151(12 \%)$ were only TPHA positive at enrolment. Women reactive for both $R P R$ and TPHA were slightly older, had less frequently been to school, and had worked as a prostitute for a longer time period than women with negative syphylis serology (table 1). All other variables were similar in both groups, except for a lower proportion of women with syphilis engaging in anal sex. Reported regular condom use was low in both groups: $8 \%$ among syphilis patients and $13 \%$ among the other women. The prevalence of STD at enrolment was similarly high among both groups. Genital ulcer disease (GUD) was present in $7 \%$ of syphilis patients and in $4 \%$ of the other women, but this difference was not significant. However, women with positive syphilis serology had more frequently a history of pubic lice infestation during the previous five years ( $62 \%$ vs $48 \%, \mathrm{p}<0.001)$, as well as antibody against Haemophilus ducreyi, suggestive of an earlier episode of chancroid ( $87 \%$ vs $62 \%, \mathrm{p}<0.001$ ).

There were no differences between HIVpositive and HIV-negative study participants with respect to age, age at first sexual intercourse, time in prostitution and sexual practices, as has been described elsewhere. ${ }^{14}$

Table 2 shows the results of the quantitative RPR and TPHA serologies at enrolment by HIV serostatus among the 193 patients. Seventy-two patients (37\%) were HIV-positive and 121 (63\%) were HIV-negative. Among HIV-positive patients, 59 (82\%) had an RPR titre of less than $1: 8$, compared to $69 \%$ in HIV-negative women $(p=0.06)$. The geometric mean titre (GMT) of the RPR results at enrolment was significantly lower among HIV-positive women (GMT 2.6) than 
Table 2 Comparison of quantitative syphilis serology in $H I V$-positive and HIV-negative women before therapy

\begin{tabular}{lcll}
\hline & $\begin{array}{c}H I V \text {-positive } \\
(n=72)\end{array}$ & $\begin{array}{c}\text { HIV-negative } \\
(n=121)\end{array}$ & p-value \\
\hline RPR titre & $\mathrm{n}(\%)$ & $\mathrm{n}(\%)$ & \\
$1: 1$ & $24(33 \cdot 3)$ & $25(20 \cdot 7)$ & \\
$1: 2$ & $24(33 \cdot 3)$ & $34(28 \cdot 1)$ & \\
$1: 4$ & $11(15 \cdot 3)$ & $24(19 \cdot 8)$ & \\
$1: 8$ & $5(6 \cdot 9)$ & $20(16 \cdot 5)$ & \\
$1: 16$ & $4(5 \cdot 6)$ & $10(8 \cdot 3)$ & \\
$1: 32$ & $3(4 \cdot 2)$ & $2(1 \cdot 7)$ & \\
$1: 64$ & $1(1 \cdot 4)$ & $2(1 \cdot 7)$ & \\
$1: 128$ & $0(0 \cdot 0)$ & $4(3 \cdot 3)$ & 0.01 \\
GMT* & $1: 2 \cdot 6$ & $1: 3 \cdot 8$ & \\
& & & \\
TPHA titre & & & \\
$1: 80$ & $0(0 \cdot 0)$ & $3(2 \cdot 5)$ & \\
$1: 160$ & $5(6.9)$ & $3(2 \cdot 5)$ & \\
$1: 320$ & $6(8 \cdot 3)$ & $1(0 \cdot 8)$ & \\
$1: 640$ & $7(9 \cdot 7)$ & $8(6 \cdot 6)$ & \\
$1: 1280$ & $14(19 \cdot 4)$ & $14(11 \cdot 6)$ & \\
$1: 2560$ & $9(12 \cdot 5)$ & $18(14 \cdot 9)$ & \\
$1: 5120$ & $14(19 \cdot 4)$ & $29(24 \cdot 0)$ & \\
$1: 10240$ & $17(23 \cdot 6)$ & $45(37 \cdot 2)$ & \\
GMT & $1: 2153$ & $1: 3589$ & 0.005 \\
\hline
\end{tabular}

${ }^{\star}$ GMT $=$ Geometric Mean Titre.

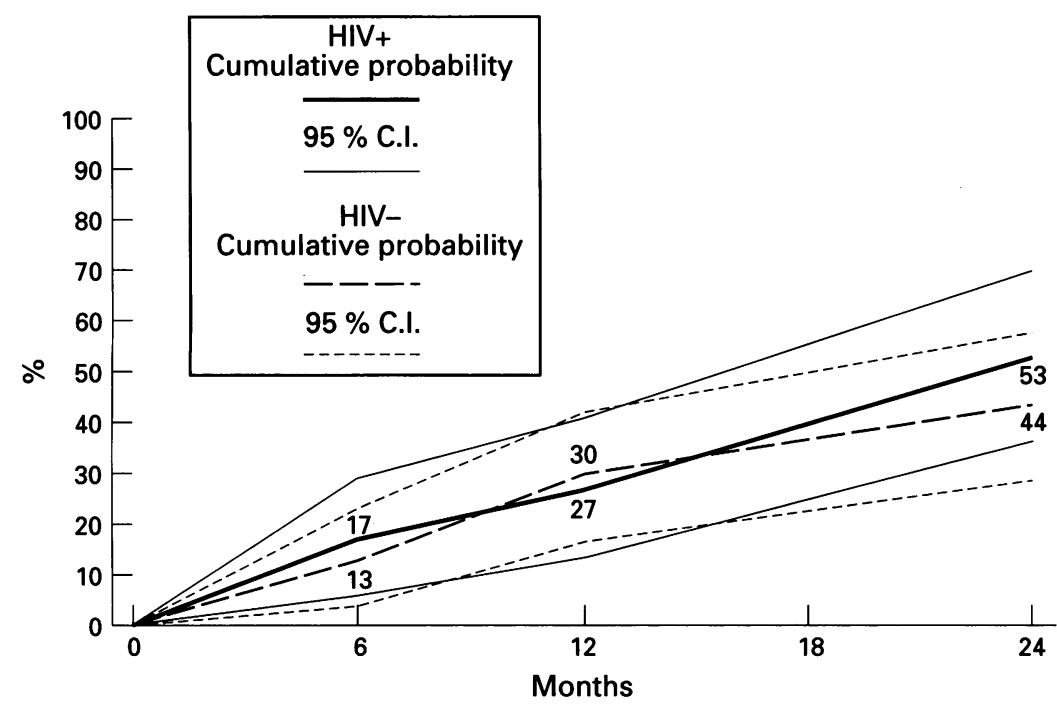

Figure 1 Cumulative probabilities of RPR-seroreversal in $H I V(+)$ and $H I V(-)$ women with initial RPR titre $<8$

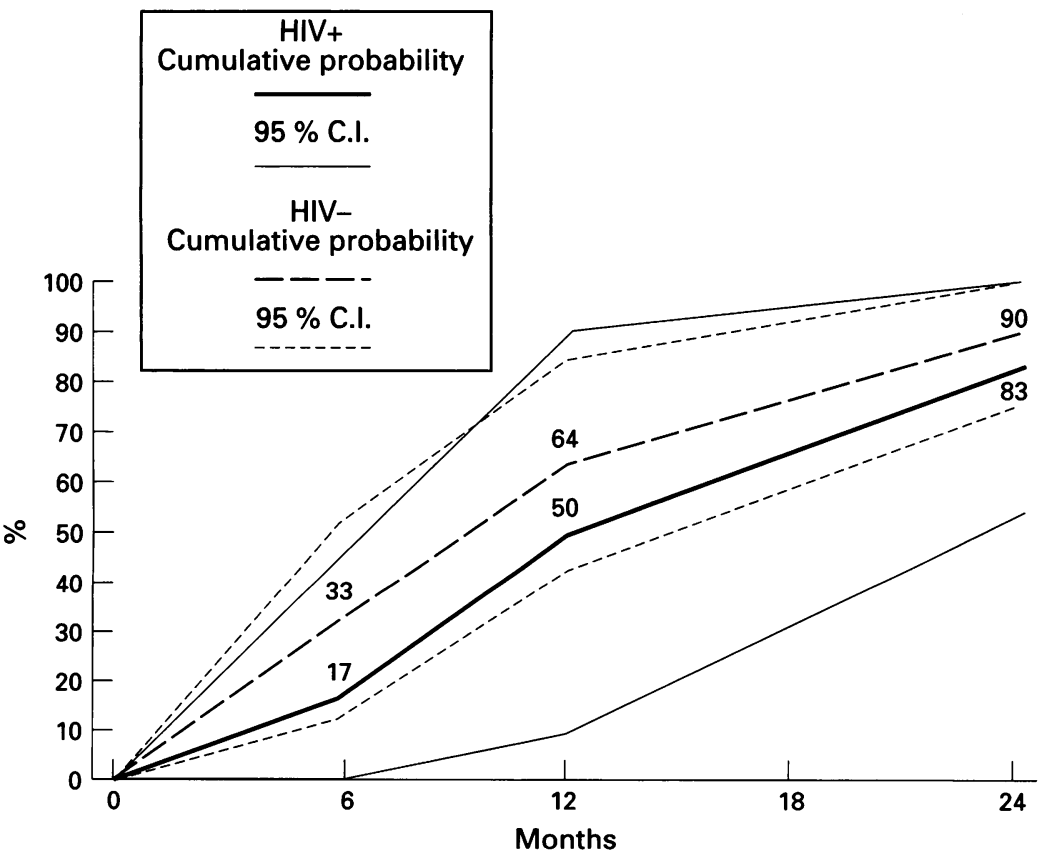

Figure 2 Cumulative probabilities of a fourfold or stronger decline of RPR titres in $H I V(+)$ and $H I V(-)$ women with initial RPR titre $>8$. among HIV-negative women (GMT 3.8, $p=0.01)$. Similarly the GMT of TPHA results in HIV-positive women was significantly lower than HIV-negative women, with 2153 versus 3589 respectively $(p=0 \cdot 005)$.

\section{Serological response to treatment}

Longitudinal data were available for 120 participants: 47 HIV-positive (65\%) and 73 HIV-negative patients $(60 \%)$. The distribution of RPR titres was similar among women who participated in the longitudinal study and the 193 syphilis patients at enrolment.

Follow-up RPR titres were available from 41 HIV-positive and 52 HIV-negative patients with an RPR titre of less than 1:8 at enrolment (table 3). Negative RPR results were observed in $27 \%$ of the HIV-positive patients presenting at the six months' visit, in $15 \%$ one year after treatment, and in $39 \%$ of the women presenting after two years. Among HIV-negative patients, a negative RPR test was observed in $15 \%, 21 \%$ and $21 \%$, respectively. There was no significant difference between the HIV-positive and HIV-negative women at any of the three time points (at six

Table 3 Evolution of RPR titres in HIV-positive and $H I V$-negative syphilis patients with an initial RPR titre of less than 1:8

\begin{tabular}{lcc}
\hline$R P R$ result & $\begin{array}{l}H I V \text {-positive } \\
n=41(\%)\end{array}$ & $\begin{array}{l}\text { HIV-negative } \\
n=52(\%)\end{array}$ \\
\hline month 6 & $(\mathbf{N}=26)$ & $(\mathbf{N}=47)$ \\
Became seronegative & $7(27)$ & $7(15)$ \\
$\geqslant$ fourfold decline & $0(0)$ & $0(0)$ \\
Stable & $16(61)$ & $38(81)$ \\
$\geqslant$ fourfold increase & $3(12)$ & $2(4)$ \\
month 12 & $(\mathbf{N}=26)$ & $(\mathbf{N}=38)$ \\
Became seronegative & $4(15)$ & $8(21)$ \\
$\geqslant$ fourfold decline & $0(0)$ & $2(5)$ \\
Stable & $20(77)$ & $22(58)$ \\
$\geqslant$ fourfold increase & $2(8)$ & $6(16)$ \\
month 24 & $(\mathbf{N}=23)$ & $(\mathbf{N}=29)$ \\
Became seronegative & $9(39)$ & $6(21)$ \\
$\geqslant$ fourfold decline & $2(9)$ & $1(3)$ \\
Stable & $12(52)$ & $20(69)$ \\
$\geqslant$ fourfold increase & $0(0)$ & $2(7)$ \\
\hline
\end{tabular}

Table 4 Evolution of RPR titres in HIV-positive and $H I V$-negative syphilis patients with an initial $R P R$ titre $\geqslant 1: 8$

\begin{tabular}{|c|c|c|}
\hline$R P R$ result & $\begin{array}{l}H I V \text {-positive } \\
n=6(\%)\end{array}$ & $\begin{array}{l}H I V \text {-negative } \\
n=21(\%)\end{array}$ \\
\hline month 6 & $(\mathbf{N}=\mathbf{3})$ & $(\mathbf{N}=18)$ \\
\hline $\begin{array}{l}\text { Became seronegative } \\
\geqslant \text { fourfold decline } \\
\text { Stable } \\
\geqslant \text { fourfold increase }\end{array}$ & $\begin{array}{l}0(0) \\
1(33) \\
2(67) \\
0(0)\end{array}$ & $\begin{array}{l}0(0) \\
7(39) \\
11(61) \\
0(0)\end{array}$ \\
\hline month 12 & $(\mathbf{N}=5)$ & $(\mathbf{N}=11)$ \\
\hline $\begin{array}{l}\text { Became seronegative } \\
\geqslant \text { fourfold decline } \\
\text { Stable } \\
\geqslant \text { fourfold increase }\end{array}$ & $\begin{array}{l}0(0) \\
2(40) \\
3(60) \\
0(0)\end{array}$ & $\begin{array}{l}0(0) \\
6(55) \\
5(45) \\
0(0)\end{array}$ \\
\hline month 24 & $(\mathbf{N}=\mathbf{3})$ & $(\mathbf{N}=5)$ \\
\hline $\begin{array}{l}\text { Became seronegative } \\
\geqslant \text { fourfold decline } \\
\text { Stable } \\
\geqslant \text { fourfold increase }\end{array}$ & $\begin{array}{l}0(0) \\
2(67) \\
1(33) \\
0(0)\end{array}$ & $\begin{array}{l}1(20) \\
3(60) \\
1(20) \\
0(0)\end{array}$ \\
\hline
\end{tabular}


months: $p=0.2$; at one year: $p=0.7$; after two years: $p=0 \cdot 25$ ). Figure 1 shows the cumulative probabilities and the $95 \%$ confidence intervals $(95 \% \mathrm{CI})$ of the RPR becoming negative at the three time points, which were similar among women with and without HIV infection.

Among women with an initial RPR titre of 1:8 or more, a fourfold or more important decline of the RPR titre was seen in $33 \%$ of HIV-positive women when presenting at the month six visit, $40 \%$ at one year and $67 \%$ at two years (table 4). The corresponding figures for HIV-negative patients were $39 \%, 55 \%$ and $80 \%$, respectively. There was no significant difference at any of the three observed time points. The cumulative probabilities of attaining a fourfold or greater decline of RPR titres as presented in figure 2 , were also similar for HIV-negative and HIV-positive patients at the three time points.

\section{Discussion}

Data on the response to therapy in women with syphilis and concomitant HIV infection are scarce. This study suggests that although initial RPR and TPHA titres were higher in HIV-negative compared with HIV-positive women, serological response (measured by RPR titres) to conventional therapy, is similar in both groups.

Presumptive diagnosis of active syphilis was made on the presence of a positive RPR and a positive TPHA serology. RPR titres lower than 1:8 dilutions were predominant among our study population, both in HIV-positive and HIV-negative women. Low titres are most common at the very beginning of the infection (primary syphilis), during the later stage (late latent syphilis of more than two years duration) and after adequate treatment, or may be due to non venereal treponematoses. ${ }^{17} \mathrm{We}$ assume that in the present study most cases were in the late latent stage because the patients had been engaged in high risk sexual behaviour for a long time and might have contracted syphilis many years before. Early syphilis cases would have been detected at a follow-up visit and endemic syphilis is thought to be rare in Zaire now. Genital ulcers were only present in $7 \%$ of syphilis cases at enrolment compared with $4 \%$ of women with negative syphilis serology. Furthermore, syphilis patients more frequently had antibodies against $H$ ducreyi. Positive $H$ ducreyi serology was associated with a history of GUD in the previous five years, while positive syphilis serology was not, suggesting that more cases of GUD in the study population are caused by $H$ ducreyi than $T$ pallidum. However, the strongest argument for late latent stage is the evolution of RPR titres in HIV-negative patients after treatment. In the early stages of syphilis, the RPR titres should have declined more rapidly and in a higher proportion of patients. ${ }^{18} 19$

Among the HIV-negative women with low initial RPR titres in the present study we found a cumulative total of $30 \%$ seroreversals
12 months after treatment, and $40 \% 24$ months after treatment. These figures are lower than those found in the treatment of early latent syphilis. In fact, they are also more consistent with the results of treatment of patients with late latent syphilis. ${ }^{20}$ Furthermore, that study also demonstrated that patients with low initial RPR titres became seronegative sooner than patients with higher initial RPR titres. ${ }^{20}$ Both observations are consistent with our data among HIV-negative syphilis patients, of whom only $44 \%$ of those with an initial RPR titre lower than $1: 8$ seroreversed.

The effect of HIV on the performance of serology for the diagnosis of syphilis remains controversial. ${ }^{5}{ }^{21}$ All reports have been on patients with early syphilis. Very little information is available on alterations of syphilis serology in HIV-positive patients with late latent syphilis. Dowell et al found that $88 \%$ of their patients with latent syphilis had an RPR titre greater than or equal to $1: 16 .{ }^{22}$ They argued that these were higher-than-expected titres because they were higher than the RPR titres observed in an earlier study among HIV-negative patients with late latent syphilis. ${ }^{20}$ In our population, the RPR results among HIV-positive and HIV-negative patients with syphilis are more in line with the results obtained in Fiumara's study. ${ }^{20}$ In both groups, low RPR titres were predominant, but HIV-positive patients had lower GMTs of RPR than the HIV-negative patients. The difference could not be attributed to factors such as differences in mean age, duration of prostitution or sexual exposure, since the two groups were comparable with regard to these variables.

Regardless of the pre-treatment RPR titre, the serological response to syphilis therapy (measured by evolution of RPR titres) was similar in HIV-positive and HIV-negative subjects. The probability of the RPR titre declining fourfold or more after the two year period was $83 \%$ in HIV-positive and $90 \%$ in HIV-negative patients with an initial RPR titre of $1: 8$ or more. However, since there were only six HIV-positive patients with high initial RPR titres, the $95 \%$ confidence intervals were very large and the results must therefore be interpreted with caution, especially since the stage of HIV disease of these women is not known and serological response may vary with stage of disease. It should also be noted that only $20 \%$ of HIV-negative and none of six HIV-positive patients with an initial RPR titre of $1: 8$ or more became RPR seronegative after two years.

The similar response to therapy observed among HIV-positive and HIV-negative women conforms to results obtained by some other investigators. In a study on the efficacy of syphilis therapy among HIV-positive and HIV-negative male intravenous drug users with different stages of syphilis in New York City, HIV infection did not alter the response to treatment. All $26 \mathrm{HIV}$-positive and 16 of 17 HIV-negative patients responded well to therapy. ${ }^{23}$ In another study among $56 \mathrm{HIV}$ - 
positive and $274 \mathrm{HIV}$-negative patients with early syphilis, the serological response to treatment was similar in both groups and no clinical failures were observed. ${ }^{24}$ However, in a case-control study in New York City, HIVpositive patients with primary syphilis showed a decreased serological response to therapy as compared to HIV-negative patients with primary syphilis. For patients with secondary syphilis this response was independent of the HIV-serostatus. ${ }^{13}$

In this study, patients received the therapy recommended by the CDC and the WHO for late syphilis (that is, late latent syphilis of more than two years' duration but otherwise of unknown duration, late benign syphilis), namely benzathine penicillin $G, 2.4$ million units intramuscular weekly for three consecutive weeks. We opted for this treatment schedule. for all patients because the duration of the infection was unknown in virtually every patient. The efficacy of this treatment schedule among HIV-positive patients has been put in doubt in recent times. Neurosyphilis may be more frequent among HIVpositive syphilis patients even after receiving supposedly adequate penicillin therapy, ${ }^{25-26}$ possibly because of the low concentrations of this antibiotic in the cerebrospinal fluid (CSF). However, in view of our results, and particularly in a developing world setting, the current recommended schedule with benzathine penicillin remains the most feasible option, because of its low cost and the ease of administration.

The results of this study confirm results from prior studies that syphilis serology (both RPR and TPHA) may be altered in HIV infection but suggests that the serological response to therapy is similar in both HIVpositive and HIV-negative patients.

This work was supported in part by the European Community Programme on Science and Technology for Development, Programme on Science and Technology for Development, AIDS Task Force of the EC, the Rockefeller Foundation, the Bank.

1 Cameron DW, Simonsen JN, D'Costa LJ, et al. Female to male transmission of human immunodeficiency virus type 1: risk factors for seroconversion in men. Lancet type 1: risk

2 Darrow WW, Echenberg DF, Jaffe HW, et al. Risk factors for human immunodeficiency virus (HIV) infections in homosexual men. Am F Public Health 1987;77:479-83.

3 Holmberg SD, Stewart JA, Gerber AR, et al. Prior herpes simplex virus type 2 infection as a risk factor for HIV infection. $\mathcal{F} A M A$ 1988;259:1048-50.
4 Quinn TC, Cannon RO, Glasser D. The association of syphilis with risk of human immunodeficiency virus infection in patients attending sexually transmitted diseases clinics. Arch Intern Med 1990;150:1297-302.

5 Hutchinson CM, Rompalo AM, Reichart CA, Hook EW III. Characteristics of patients with syphilis attending Baltimore STD clinics. Multiple high-risk subgroups and interactions with human immunodeficiency virus. Arch Intern Med 1991;151:511-6.

6 Berger JR. Neurosyphilis in human immunodeficiency virus type 1 seropositive individuals. A prospective study. Arch Neurol 1991;48:700-2.

7 Gregory N, Sanchez M, Buchness MR. The spectrum of syphilis in patients with human immunodeficiency virus infection. F Am Acad Dermatol 1990;22:1061-7.

8 Johns DR, Tierney M, Felsenstein D. Alteration in the natural history of neurosyphilis by concurrent infection with the human immunodeficiency virus. $N$ Engl $f \mathrm{Med}$ 1987;316:1569-72.

9 Centers for Disease Control and Prevention. 1993 sexually transmitted diseases treatment guidelines. $M M W R$ 1993;42(No. RR-14):27-46.

10 World Health Organization. STD Treatment Strategies. WHO Consultation on Development of Sexually Transmitted Diseases Treatment Strategies. WHO/ VDT/89.447; p. 9-14.

11 Hicks CB, Benson PM, Lupton GP, Tramont EC Seronegative secondary syphilis in a patient infected with the Human Immunodeficiency Virus (HIV) with Kaposi Sarcoma. A diagnostic dilemma. Ann Intern Med 1987; 107:492-5.

12 Hook EW III. Syphilis and HIV infection. $\mathcal{F}$ Infect Dis 1989;160:530-4.

13 Telzak EE, Zweig Greenberg MS, Harrison J, Stoneburner RL, Schultz S. Syphilis treatment response in HIV infected individuals. AIDS 1991;5:591-5.

14 Nzila N, Laga M, Manoka AT, et al. HIV and other sexually transmitted diseases among female prostitutes in Kinshasa. AIDS 1991;5:715-21.

15 Laga M, Manoka A, Kivuvu M, et al. Non-ulcerative sexually transmitted diseases as risk factors for HIV-1 transmission in women: results from a cohort study. AIDS mission in wom

16 Colton $\mathrm{T}$. Longitudinal studies and the use of the life table. In: Colton $\mathrm{T}$, ed Statistics in Medicine. Little, Brown and Company, Boston, 1974, p. 237-250.

17 Hart G. Syphilis tests in diagnostic and therapeutic decision making. Ann Intern Med 1986;104:368-76.

18 Romanowski B, Sutherland R, Fick GH, Mooney D, Love EJ. Serologic response to treatment of infectious syphilis. Ann Intern Med 1991;114:1005-9.

19 Fiumara NJ. Treatment of early latent syphilis of less than a year's duration: an evaluation of 275 cases. Sex Transm a year's duration:

20 Fiumara NJ. Serologic responses to treatment of 128 patients with late latent syphilis. Sex Transm Dis 1979;6: 243-6

21 Hamill RJ, Baughn RE, Musher DM. Recognition of Treponema pallidum antigens by IgG and IgM antibodie in HIV-infected patients with syphilis. 29th Annual Intersci Conf Antimicrob Agents Chemother. Washington, DC. American Society for Microbiology, 1989. [Abstract 949].

22 Dowell ME, Ross PG, Musher DM, Cate TR, Baughn RE. Response of latent syphilis or neurosyphilis to ceftriaxone therapy in persons infected with human ceftriaxone therapy in persons infected with hum

23 Gourevitch MN, Selwyn PA, Davenny K, et al. Effects of HIV infection on the serologic manifestations and response to treatment of syphilis in intravenous drug users. Ann Intern Med 1993;118:350-5.

24 Rolfs RT, Hinderschot E, Hackett K, et al and the Syphilis \& HIV Study Group. Treatment of early syphilis in HIV-infected and HIV-uninfected patients. Preliminary results of the Syphilis \& HIV study. Tenth International Meeting of the International Society for STD Research Meeting of the International Society for

25 Lukehart SA, Hook III EW, Baker-Zander SA, Collie AC, Critchlow CW, Handsfield HH. Invasion of the central nervous system by Treponema pallidum Implications for diagnosis and treatment. Ann Intern Med 1988;109:855-62.

26 Musher DM. Syphilis, neurosyphilis, penicillin, and AIDS. F Infect Dis 1991;163:1201-6. 